\title{
GIS and infrared aerial view: advanced tools for the early detection of environmental violations
}

\author{
M. Lega ${ }^{1} \&$ G. Persechino ${ }^{2}$ \\ ${ }^{1}$ Department of Engineering, University of Naples Parthenope, Italy \\ ${ }^{2}$ CIRA, Italian Aerospace Research Center, Italy
}

\begin{abstract}
Environmental violation is an illegal act that harms the environment or endangers public health, offending federal, state or local laws. When the environmental violation is excessive or the violator is a repeat offender, it evolves into environmental crime. Environmental crime is a relatively new concept and is ever changing. To guarantee the safety and security of the public, environmental laws regulate all activities that have a negative effect on human health, harm a community or the environment. The citizens' exposure to pollution and/or to dangerous wastes is a major public health problem; therefore, public authorities must act as quickly as possible to identify such environmental issues. An early identification of environmental criticalities would reduce citizens' exposure risks and remediation costs. The most suitable solution to detecting environmental criticalities and preventing environmental crime is targeted and effective environmental monitoring. In this paper it will be shown how our integrated system, which includes aerial platforms and ad-hoc sensors (e.g. infrared cameras, multispectral sensors, etc.), can be an effective tool to ensure environmental and human safety and security. Our monitoring and measurement protocol has been developed to answer the needs of environmental enforcement. Thus the technique demonstrated here can ensure a wide coverage area, is cost effective, in terms both of time and money, and provides highly precise measurements with few false alarms. The proposed procedures, techniques and technologies were tested and validated in environmental police actions directed by Italian government bodies (Public Prosecutor, Environmental
\end{abstract}


Protection Agency, Coast Guard, Financial Police, Forest Rangers etc.) in real, in the field operations.

Keywords: environmental violations, environmental enforcement, eco crimes, public health, aerial infrared thermography, GIS.

\section{Introduction}

The "test-bed" of our activities is the Campania region in south-east Italy, where the accumulation of wastes (illegal and legal, urban and industrial) has contaminated soil, water, and the air but, mainly, in a specific area between the cities of Caserta and Naples, today called "land of fires".

Much of this was caused by illegal activities of the Camorra (the name of a dominant Naples mafia clan), and criminal behaviour of corrupt politicians, public administrators, and company managers. Hazardous wastes were routinely being dumped in quarries and on farmland, illegal landfills were being constructed, wastes were being burned illegally on farm land, industrial and agricultural wastes were being discharged into streams and other water bodies, and the Domitian coast was becoming the repository for a wide variety of wastes.

There is a tremendous amount of money to be made through these illegal activities.

The opportunity of profit in this area responds to a simple market rule: the match supply with demand. Indeed Naples and its suburban area is a high population density area with a high demand of waste management services and disposal sites, but the same area supplies only few and already filled landfills and the approach to waste management is not optimised (e.g. separate collection of rubbish is absent or rare). An apparent effective and efficient solution came from "Camorra company", that decided to invest on the business of waste management, optimizing the efficiency with the reduction of the costs; for years they have collected wastes and buried them in caves, small lakes and farmland with zero costs obviously in illegal ways and with no respect for the human health. Moreover Camorra found this business so attractive that extended the waste management service in other regions and sometimes in other country continuing dumping in the same disposal area: the Campania region.

This paper is focused on methods and procedures developed by our research group for the discovery of illegal disposal sites (quarries, small lakes, farmland etc.) often used by Camorra for their main activities. The novelty of our work is related with the integration of different processes, partly connected with the use of information tools, partly connected with data grabbed on the field.

The most challenging goal is to find right relations between the "smart" criminal minds and the eco-crimes evidences.

Being able to identify environmental crimes and the guilty parties is central to police investigations, and new technologies enable authorities to do this faster and more accurately than ever before. In recent years, our research team has introduced the use of a range of aerial platforms and an innovative application of thermography to detect several illegal activities; for example illegal sanitary 
sewer and storm-drain connections, illicit wastewater discharges and other "anomalies" on surface waters can be easily identified using their thermal infrared (IR) signatures. It can also be used to detect illegal solid/liquid waste dumps or illicit air discharges.

Having a good knowledge of the physical phenomena and their effects on the environmental matrices, it is possible to identify natural events from human related ones, even in a complex scenario. Moreover, starting from the evidence of an environmental damage, it's possible to search the causes and to define the source-path-target model.

In recent years, wide knowledge has been gained by the scientific community about evidence connected to the analysis of photos and the chemical, physical, and biological data acquired at a crime scene, but few references on the use of radiometric data (by IR cameras) and their representation exist. This is particularly true for the use of these data and their interpretation for the study and analyses occurring during environmental police investigations.

Today, a conventional criminal investigation begins with the evidence of the crime that defines the scenario to be investigated. Similarly, for environmental crimes, the investigation often begins with the evidence of the damage rather than of the illegal polluting act. Often the consequences of pollution appear in a different place from or a long time after the polluting act has been committed, and the correlation between the source and the damage depends upon the morphology of the scenario and the physical phenomena that permit the transport of the pollutants. For these reasons the environmental police investigations must be realized by alternating bottom-up and top-down approaches. In order to increase the effectiveness of the investigations, the human senses can be "augmented" using additional advanced sensors and the power of information technology Lega et al. [1].

The proposed procedures, techniques and technologies were tested and validated in environmental police actions directed by Italian government bodies (Public Prosecutor, Environmental Protection Agency, Coast Guard, Financial Police, Forest Rangers etc.) in real, in the field operations.

\section{Materials and methods}

The visualization of spatial relationships of natural and man-made features can focus the scope of environmental investigation, and provide a simple, yet quantitative, historical record of changes in conditions on a site.

Technologies such as geographic information systems (GIS) enable geospatial information to be captured, updated, integrated, and mapped easily and economically. These technologies create both opportunities and challenges for achieving wider and more effective use of geospatial information in stimulating and sustaining sustainable development through smart policy making.

Environmental applications include analysis of source, extent and transport of contaminants, nonpoint runoff modelling, flood control, and emergency response support. The ability to examine spatial relationships between environmental 
observations and other mapped and historical information, and to communicate these relationships to others, makes GIS valuable in environmental forensics Brilis et al. [2].

Geographic information systems and spatial analysis techniques, in particular, are proving to be essential for studying criminal activity but the effectiveness of a GIS in environmental forensics is often related to the number of the data/layers managed by the system and the specific know-how of the expert involved in the investigation activity.

Each GIS includes a set of interactive maps and other views that show features and relative relationships on the earth's surface. Various map views of the underlying geographic information can be constructed to support query, analysis, and editing of geographic information. Maps can also be used to access geographic modelling tools that are used to derive new information.

A GIS has a comprehensive set of analytic and data transformation tools to perform spatial analysis, data processing and geo-statistical analysis.

During the past years our research team has extensively used GIS and has particularly cooperated with CIRA in the development of IDES project.

IDES - Intelligent Data Extraction System - project aims at implementing a SW platform for data analysis within the domain of environmental criticalities.

IDES offers an integrated repository of information extracted from heterogeneous, physically distributed, unstructured sources (satellite and airborne data, web pages, etc.) by means of a capture, extraction and analysis process. Based upon the integrated information stored in a Geographic Information System and elaborated with the aid of advanced data analysis techniques and tools, IDES is able to extract the hidden information, that is information non immediately identifiable through a mere reading or a deeper analysis, even if performed by a domain expert; at this end, IDES is able to uncover patterns, multi-disciplinary correlations not known a priori and to extract relevant information useful for Government Bodies, Persechino et al. [3].

This paper introduces a first example of the combined use of GIS system and the advanced analysis of data sampled on the field; in detail we focused our activities in the development of a new method for the discovery of wastes buried illegally in quarries, small lakes and farmland.

An example of analysis for the discovery of a quarry no longer used and transformed in illegal and dangerous landfill is introduced in this paper.

Analysis of the data on a GIS system (ARCGIS SW) allowed us to identify a number of quarries suspected of being potential illegal locations for waste storage.

An example of a GIS analysis of the area of Caserta province is reported below; in particular, the following data/layers have been reported on map: quarries, landfills, river basin, city grids, road networks, population centres (Fig. 1, 2).

We have searched for not longer used quarries in the proximity of a road network such as to allow the transit of large truck suitable for the transport of wastes (Fig. 3). 

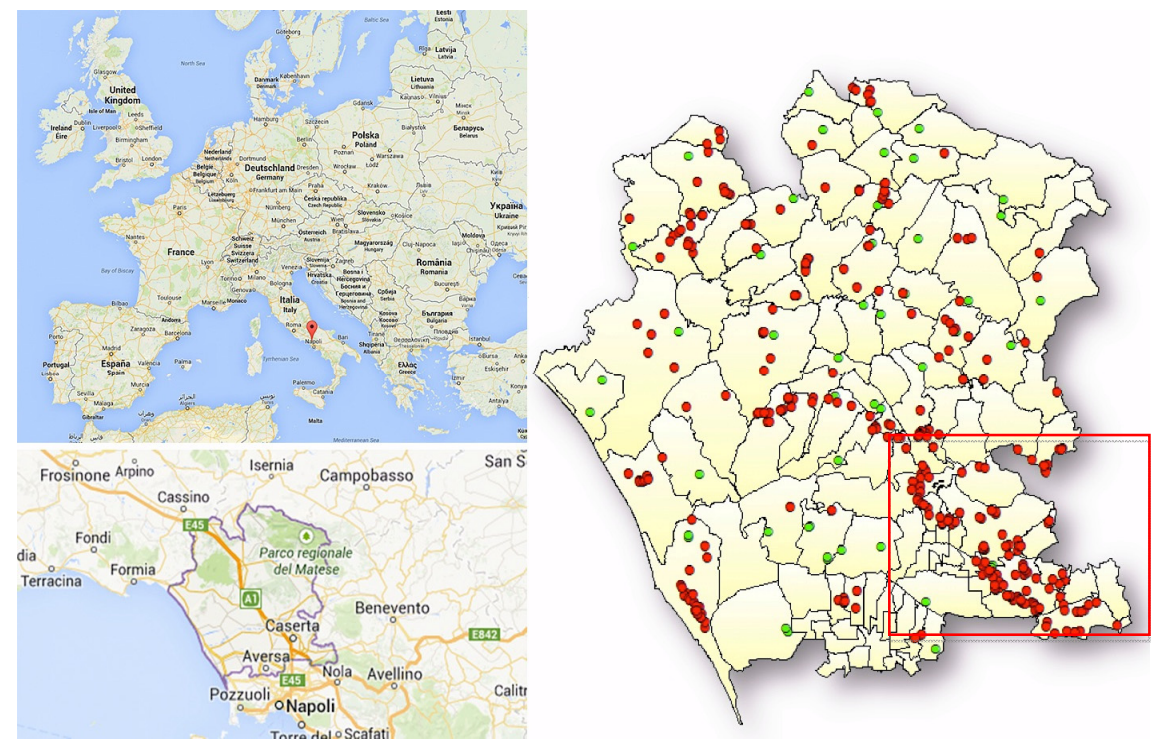

Figure 1: Quarries and landfills in the county of Caserta (Italy - Campania region).

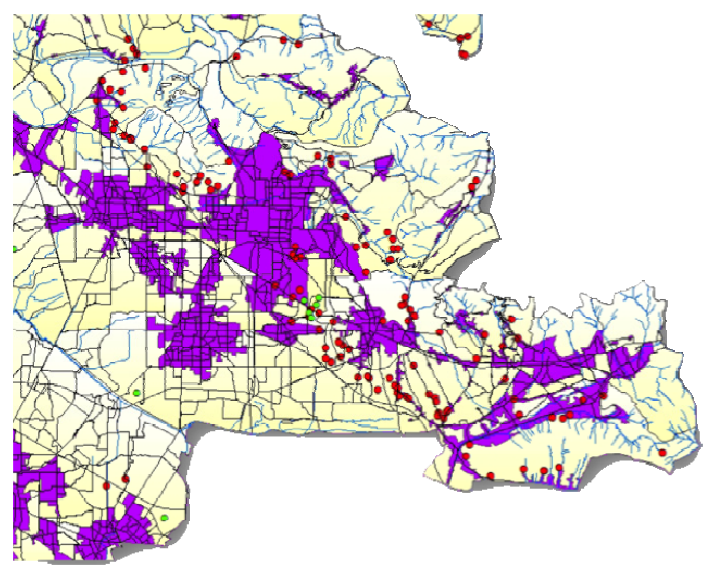

Figure 2: Map detail of Caserta County, focussed on a layers "overlap" that includes: quarries, landfills, river basin, city grid, road network and population centres.

Furthermore, the position of these quarries has been compared with existing landfills and the towns that could "feed" with their production of waste the offering the illicit service. 


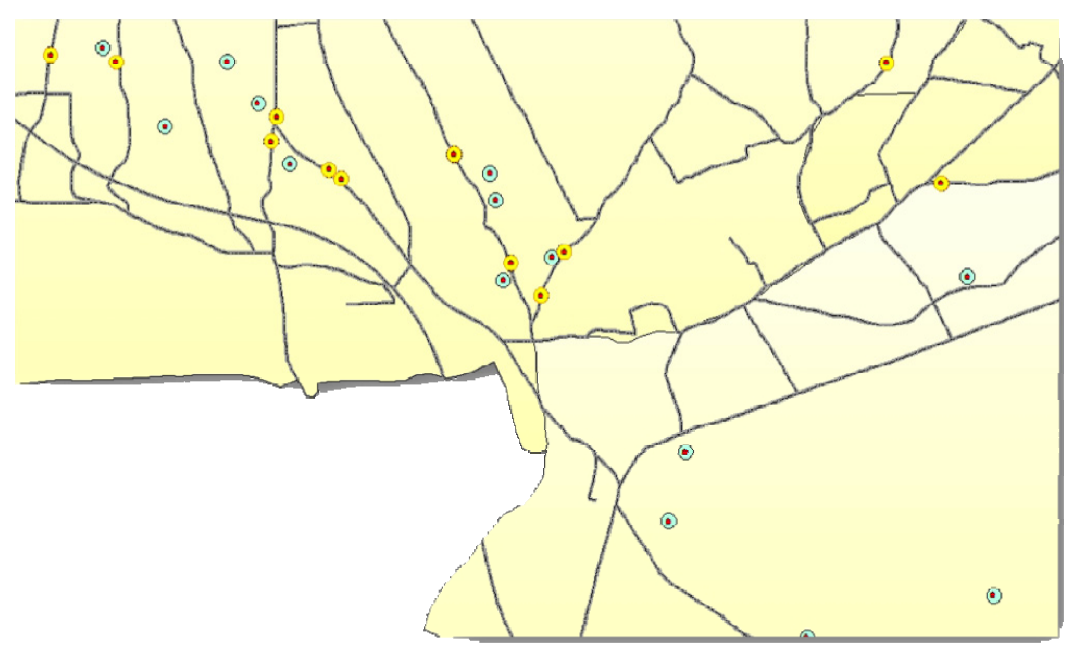

Figure 3: Map detail of quarries and network road.

Finally, we have identified among the suspect quarries those in the proximity of rivers; indeed, such condition would be more critical since the same rivers may be the target of contamination and carriers to inhabited areas.

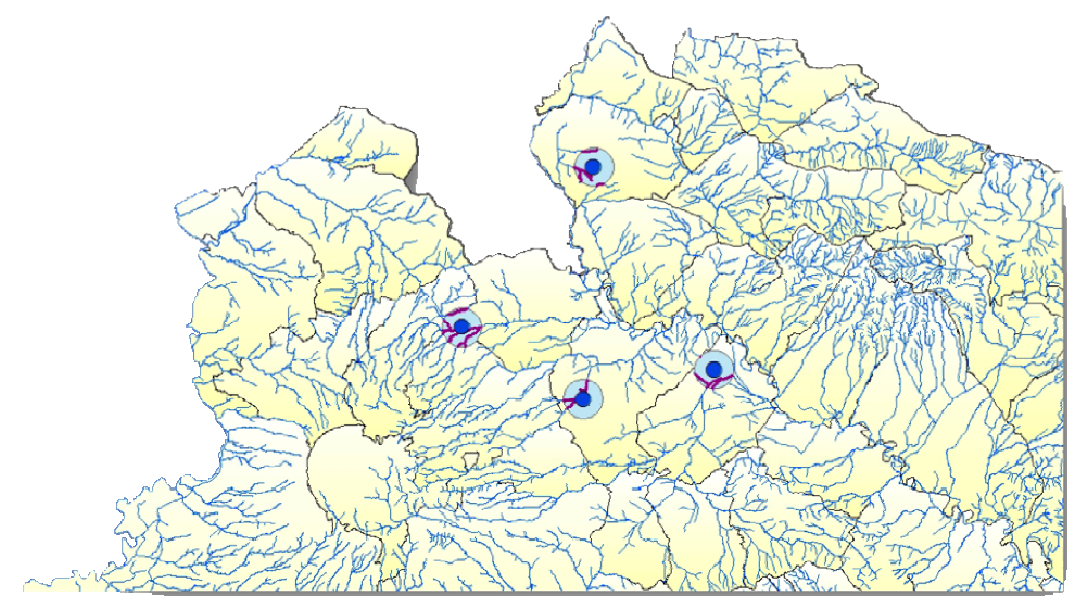

Figure 4: Map detail of quarries and river basin.

Therefore, after a careful analysis the initial number of quarries to be tested with measurements on the field has been enormously reduced, thus reducing time and costs. 
In particular, aerial thermography techniques with prevalent use of helicopters and drones were used for the field surveys; indeed by using infrared thermography, specialized aerial platforms and advanced techniques of data analysis and visualization we can discover several environmental problems: locating pollution point sources and finding right path between sources and targets (Lega and Napoli [4]).

Among the field surveys on quarries a particularly critical case is reported below as an example of the effectiveness of this method.

The scenario of our case study is a tuff stone quarry no longer used and partially transformed in illegal landfill for dangerous wastes (we suppose residual of chemical products).

Indeed, it is important to remember that a tuff quarry at the end of its life cycle/processing is like an empty swimming pool ready to be filled in and, therefore, it is a perfect place to bury waste illegally; indeed, there are no costs of excavation but it's only necessary the covering to mask the burial.

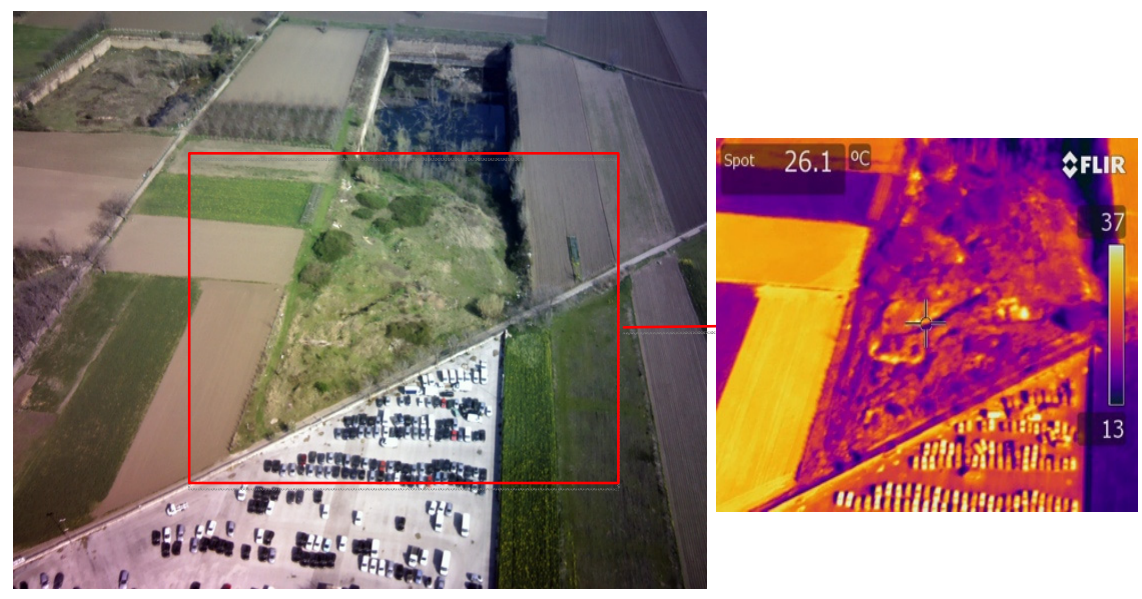

Figure 5: Aerial view of a tuff stone quarry no longer used and partially transformed in illegal landfill for dangerous wastes. On the left side an IR aerial view of the buried area.

All IR aerial views are "radiometric" data and, therefore, it is possible to quantitatively analyse them through the associated matrices.

Therefore several "transect" of measure have been located to measure the temperature changes in the specific anomalous areas.

The analysis of the charts clearly displays the presence of temperature peaks in correspondence of the suspected areas, completely anomalous for a normal green area with no geophysical phenomena.

The critical areas were also pointed out through techniques based on the analysis of the isotherms (Fig. 6), and the method of edge detection (Fig. 7). 


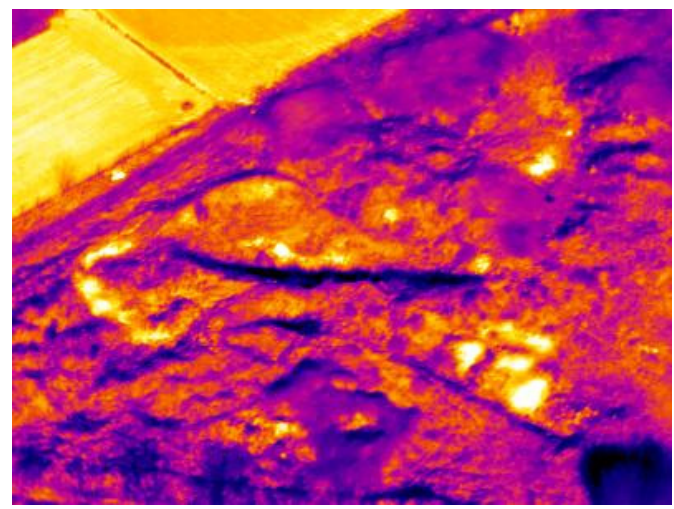

Figure 6: IR aerial view: detail of the "anomalous" spots.

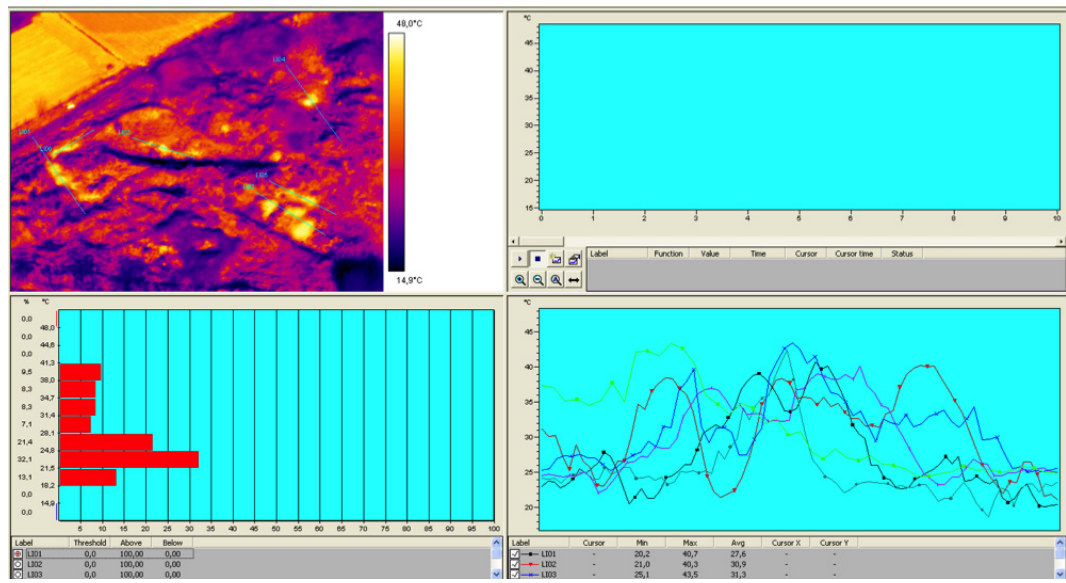

Figure 7: Analysis of IR data.

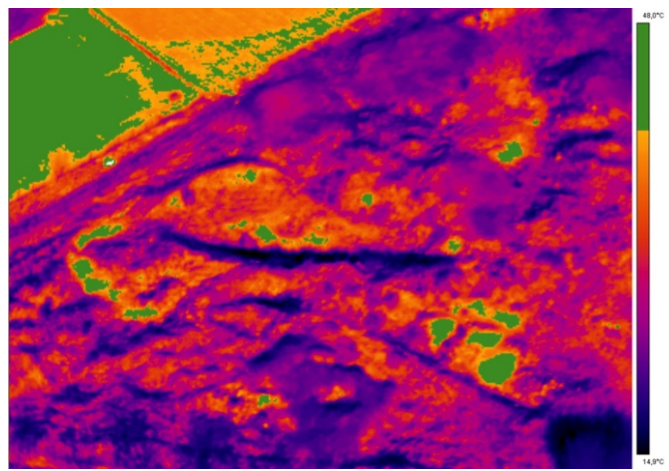

Figure 8: Highlight of "anomalies" using isothermal analysis. 


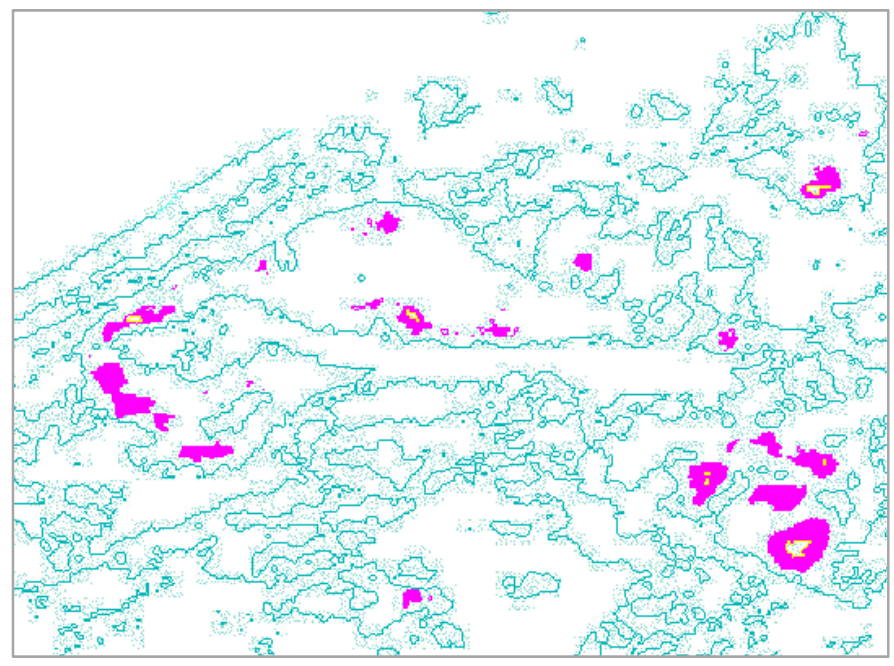

Figure 9: Highlight of "anomalies" using edge detection algorithm (Laplace) on radiometric output matrix.

\section{Results and discussion}

Authorized officers appointed by Prosecutor Office to exercise their functions under Technical Consultants supervision have extensive powers of investigation in relation to illegal dumping. There are a number of investigation tasks that can be carried out at both the place the waste was dumped ('on-site') and in the office/lab to catch and deal with offenders (Lega et al. [1]). This paper introduces the use of advanced technologies (special aerial platforms, innovative application of thermography and advanced software tools) and new methods and procedures to detect and fight this illegal activity.

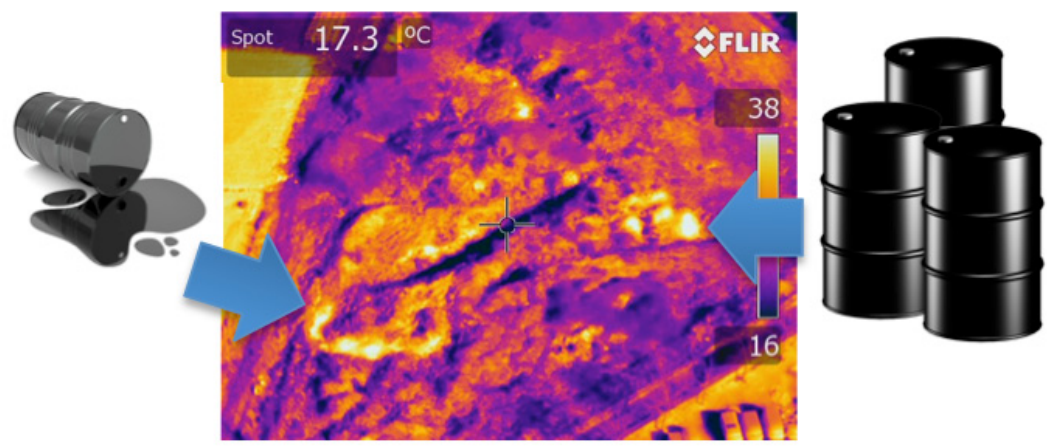

Figure 10: Buried cans. 

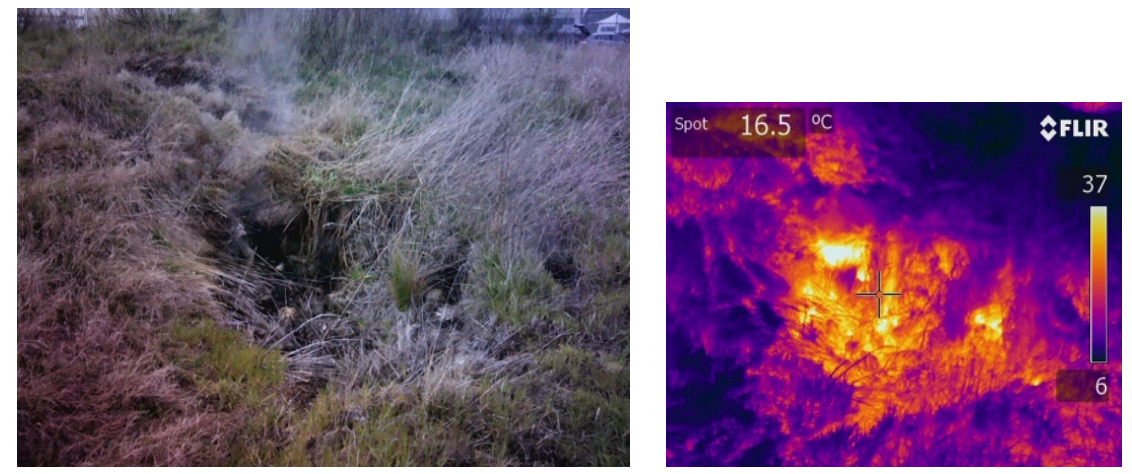

Figure 11: A detail of one of the anomalies identified during our mission on the field. We want to highlight the presence of smoke and bad odours.

\section{Conclusions}

Our developed technique shows the effectiveness of the method that combines the use of GIS and field surveys using advanced technologies but it is necessary also to highlight the efficiency of the system in terms of times and costs (indeed proceeding with a detailed analysis on field, the times and the costs would be huge and not allowing a real application on wider areas). Our method allows a drastic reduction of the areas to be analysed, focusing the surveys on the most critical ones for the concomitant presence of abnormal factors. Currently, the sequence of logical steps to be followed was verified using simple tools on the shelf (sw ARCGIS, FLIR Researcher, etc.) but hopefully the completion of the project IDES, developed by CIRA, may in the future provide an ad hoc instrument for continuous land management by government agencies, representing a key element in the mechanism of early detection of critical environmental problems. The presented application is related to a specific environmental criticality such as the quarries used as waste storage sites but it is certainly applicable to other scenarios and criticalities; indeed in the past our group has already introduced relevant advanced techniques for the analysis of air and water matrices (Lega and Napoli [5], Lega et al. [6, 8] and Persechino et al. [7]).

This paper provides an example of where law enforcement and university research teams can collaborate on developing enhanced environmental protection methods. The proposed procedures, techniques and technologies, were tested and validated in environmental police actions directed by Italian Prosecutor Office and permit to understand the forensic value of the environmental engineer.

\section{Acknowledgements}

We wish to acknowledge Claudia Ferrara for the effort in the research group and Speranza Dell'Anno for the cooperation in the analysis of the GIS data. 
We wish to acknowledge the Italian Public Prosecutor's Office in Santa Maria Capua Vetere.

Finally, we wish to thank NaturalDrones for their contribution in the development of the drones used in our field surveys.

\section{References}

[1] Lega, M., Kosmatka, J., Ferrara, C., Russo, F., Napoli, R. M. A., Persechino, G., Using Advanced Aerial Platforms and Infrared Thermography to Track Environmental Contamination, Environmental Forensics, Taylor \& Francis, 13 (4), 332-338, 2012

[2] Brilis, G. M., Waasbergenb, R. J., van Stokelyc, P. M., Gerlachd, C. L., Remote Sensing Tools Assist in Environmental Forensics. Part II: Digital tools, Environmental Forensics, Taylor \& Francis, 2 (3), 223-229, 2001

[3] Persechino, G., Lega, M., Romano, G., Gargiulo, F., Cicala, L., IDES project: An advanced tool to investigate illegal dumping, WIT Transactions on Ecology and the Environment, 173, 603-614, WIT Press, 2013

[4] Lega, M., Napoli, R. M. A., Aerial infrared thermography in the surface waters contamination monitoring, Desalination and Water Treatment, Taylor \& Francis, 23 (1-3), 141-151, 2010

[5] Lega, M., Napoli, R. M. A., A new approach to solid waste landfills aerial monitoring, WIT Transactions on Ecology and the Environment, 109, 193-199, WIT Press, 2008

[6] Lega, M., D'Antonio, L., Napoli, R. M. A., Cultural Heritage and Waste Heritage: Advanced techniques to preserve cultural heritage, exploring just in time the ruins produced by disasters and natural calamities, WIT Transactions on Ecology and the Environment, 140, 123-134, WIT Press, 2010

[7] Persechino, G., Schiano, P., Lega, M., Napoli, R. M. A., Ferrara, C., Kosmatka, J., Aerospace-based support systems and interoperability: The solution to fight illegal dumping, WIT Transactions on Ecology and the Environment, 140, 203-214, WIT Press, 2010

[8] Lega, M., Ceglie, D., Persechino, G., Ferrara, C., Napoli, R. M. A., Illegal dumping investigation: A new challenge for forensic environmental engineering, WIT Transactions on Ecology and the Environment, 163, 3-11, WIT Press, 2012 